\title{
A Historical Perspective of Four Development periods of Vocational Education
}

\author{
Yingying $\mathrm{Hu}$ \\ Huanghe Science and Technology College \\ Zhengzhou, China \\ e-mail:hyy3858@163.com
}

\begin{abstract}
The vocational education has roughly experienced four historical periods since it appeared-the period of apprenticesystem in the vocational education before world war ii, the schoolbased period of the vocational education after world war ii till $\mathbf{1 9 6 0}$, school-enterprise cooperation period of the vocational education between the 1970s to the $1980 \mathrm{~s}$, and the diversified period of the professional education since the 1980 s to present days. Each historical period of the vocational education school-running system has its own characteristics.
\end{abstract}

Keywords-Historical Perspective; vocational education; development period

\section{THE APPRENTICESHIP PERIOD OF THE OCATIONAL EDUCATION}

Between general education and occupation education, which actually happened first during the history of mankind? From the perspective of the original form of the apprenticeship, the answer is supposed to the occupation education; while from a perspective of the institutionalized education form, the answer is on the contrary, that education actually happened first. So, why the occupation education separated from the general education then has been being taught and researched? The concept of "occupation" appeared very early in the history, but as a type of education, the occupation education, is gradually formed in the transition from agricultural society to industrial society. The structure of social occupation changed distinctly after the emergence of large industry, firstly, the workers in the frontline of production need to master the necessary knowledge and skills through getting some extent specialized education or training. With this form of education expanded its scale gradually, people began thinking it is necessary to separate out this kind of education as a new research and education field in order to understand the rules better and carry out this kind of education more effectively. Service industry has been expanding and management is more complicated as a result of the development of the society, and therefore, not only frontline workers in the production field, but also those in service field, management personnel needed to get education and specialized training.

There are many features in common for this kind of education according to different occupations, while they got education and training, education practitioners also divided into the obvious hierarchy, thus formed a huge system for this kind of education, it eventually become a relatively independent education system. In the education history of China, such kind of education was called industrial education, vocational technology education, etc. In fact, the non-institutionalized apprenticeship originated in the family, and the institutionalization of the apprenticeship system originated in the medieval handicraft guild in Europe, boomed from the fourteen to fifteenth Century, beginning to collapse after the industrial revolution. After the First World War, people began to reconsider the role of apprenticeship, until now, the new apprentice system has been reformed after the formation of the modern apprenticeship. One of the training objectives of apprenticeship is cultivating semi-skilled and skilled workers, and even many professionals. Its original form is a kind of informal, non-academic teaching instead of the new skills, onthe-job-work-place, the "hand in hand" discipline system; The guild is the transformation of the original form: semiinstitutionalized, certificate will be issued, indefinite, selfemployment; and the modern apprentice system is a combination of business apprentice training and school occupation education, students got employed in the formal business after graduation..

\section{SCHOOL-BASED PERIOD OF THE VOCATIONAL EDUCATION}

The real large-scale period of the development of the occupation education was after the Second World War. It was a period of great development of the international occupation education, and also the most controversial period. First of all, from a practical perspective, occupation education has developed "climax tide", but also experienced the "low point", there has not been such a big change in such a short period of time from the perspective of the whole occupation education development history. In $60 \mathrm{~s}$ and early $70 \mathrm{~s}$ of the twentieth century, governments developed occupation education with great passion with the impact of the economic development and human capital theory, which could be named "the golden age" of the occupation education development. But later in the $70 \mathrm{~s}$, the public and governments in many countries greatly disappointed at the occupation education as the high input in the occupation education did not bring high returns as expected. Thus, 
occupation education became the "Scapegoat" of to the economic crisis from the "pet" of the economic development.

Secondly, from a theoretical point of view, there has been a large number of occupation education experts during this period, such as $\mathrm{K} \cdot \mathrm{King}$, Barlow and Blaug in Britain, Forster and $\mathrm{Sa}$ Carlo Boros in the US and so on, they all described some of the basic issues of the occupation education from different angles, and published their own different points of view. Baugh and Forster are especially the most famous among of those experts. Baugh elaborated his education thoughts in one of his book Africa catastrophe, and What Kind of School Does Africa Need, such as: one should advocate occupation education as his developing key through investing school occupation education form and reform the secondary school curriculum of occupation education; and Forster's view is reflected in his "development planning in the occupation school fallacy" published in 1965, he stated that the existence of "fallacy" in occupation education school form, and the development of occupation education should be diversified running ways and focus on the vocational or career training, and enterprise-based non-formal education as well. Besides, the change on the policy of the international organization is dramatic for the occupation education development. The world bank has changed in the past blindly invest in developing countries to achieve modernization of economic divisions since the beginning of the twentieth century and put more investment on education especially the occupation education among these countries, due to the influence of the British economist Balogh, who lead the mainstream of the development of the vocation education school form faction. But years later, the plans sponsored by the World Bank to diverse school curriculum gradually stopped, and the funding of the medium occupation school had been reduced by the influence of Forster's against at the school form occupation education. This dramatic change influenced the sustainable development of occupation education and training greatly.

After the Second World War, the whole world has entered a new and recovery period. As the economic recovery and development and the science and technology progress, so many manpower supply shortage appeared in most countries, especially some industrialized countries, such as Britain, America, Australia and other countries, were trying to ease their pressure of the domestic human recourse demand in the labor market by immigration. Therefore, an urgent requirement for the development of the occupation education was aroused, and vigorously called for developing this secondary education, especially the expansion of secondary occupation education scale, has become the basic national policy for all countries to solve such an immediate problem. Both the economic and industrial circles are proposed that they were looking forward to more able workers, especially cultivating and training a large number of skilled workers and technical staff to go to work immediately in order to meet the needs of economic recovery and development of technical progress. Therefore, the early $60 \mathrm{~s}$ and $70 \mathrm{~s}$ of the twentieth century is a peak period of educational development for many countries after the war, also "the golden age for the development of the vocational and technical education". The secondary occupation education scale has been an unprecedented expansion as the increase of the investment for the occupation education in many countries all through the world during this period, and it became the main part of the whole occupation education system since then, so it made a significant contribution to national economic development and social progress, especially, the secondary occupation education development contributed to the economic development at the end of the Second World War, furthermore, it had become an indispensable part of the secondary education system in many countries.

It is one of the development strategies of the secondary education in may developed countries that began to implement comprehensive school vigorously, which as a combined secondary education model of vocation education and general education, such as in the US, Japan. And the other strategy was to provide different secondary schools by setting up three different types of schools to different students: academic, occupation and technology. Every student can enjoy a secondary education in these countries by the scale expanding of medium education, such as in the United Kingdom. So in the current situation of manpower supply shortage, these enterprises, as the employers in the market, cannot be too picky about the human resource cultivated by vocation education, they didn't have much choice, nor put forward requirements on the quality of occupation education should have. Thus, school-based occupation education has been a feature for most of the former centrally planned economies in most European countries, and occupation education mainly were the medium occupation schools, technical schools and apprenticeship training schools. $2 / 3$ students at this age were in these education institutions, which run in parallel with the general public high schools.

Meaning while, the main demand of education was such a type that offers courses of agriculture technology at all levels of schools in large scale, due to the vast of the majority population that depend on agriculture to survive for most of the developing countries, such as in Africa, Balogh just considered that "schools must provide villages with the basis for modern agriculture", [1] and it play a core role in improving the living standards for those public groups in the developing process. So here came a problem that the current education facilities became barriers to rural development and hindered the rural development, people did not accept the agricultural education, and what's more, the normal education and academic system were the main factors for people's hostile to agricultural practice and things like that., and school was regarded as the main factor that was responsible for the rural population flew into the city.

\section{SCHOOL-ENTERPRISE COOPERATION PERIOD OF THE VOCATIONAL EDUCATION}

If the "climax point" of the development for the world's occupation education was the period after the Second World War to the 60 s of 20 century, then its "low tide" is late in 70 s of 20 century. In fact, the vocational education was facing such an 
unprecedented challenge[2]in late $60 \mathrm{~s}$ and early $70 \mathrm{~s}$ in 20 century, more input for Education (especially for the occupation education) was carried out in $70 \mathrm{~s}$ in many countries with great enthusiasm under the influence of modernization theory and human capital theory, but without high return rate as expected. What's more, the serious economic crisis and high unemployment made people felt disappointed with governments and education, especially the vocational education. As a result, it became the "Scapegoat" of the economic crisis instead of a dear "pet" of the economic development. Thus not only western education economy that based-on the theory of human capital was coerced and urged on all sides, but also the occupation education became a critical target for all sides. Therefore, public spending was cut largely in the circumstance of economic crisis and national monetary tense and the education funding was also the cutting focus, then the education scale was severely limited, including the secondary vocational education. The result was people were strongly supporting calls for education reform, so the development of secondary occupation education was difficult to go on.

On the background above, "weak" in employment and "slow" in meeting an emergency at the process in the traditional occupation education was the reality of students, and it caused people to begin thinking, as a result, the validity traditional strategy of "develop the vocational school education vigorously ", "curriculum professionalism reform of vocational school education" were queried by people. Therefore, it wasn't until mid-to-late $1970 \mathrm{~s}$ that traditional vocational education of the school-based mode was criticized and censured, then a cooperation mode that between the school-based mode with poor practical training and enterprises-based mode with poor science and technology knowledge, as a new occupation education model to adapt to the needs of the times. This cooperation education mode had advantages both from school and enterprise education, and embodied two concrete forms, one is the cooperation mode based on school education, and the other is based on enterprise training, both of whose contents and forms of organization were various. And what's more, this kind of cooperation has set up a joint coordination mechanism with comprehensive study oriented, it also had a project or technology development through signing certain contract, and offered the occupation school counseling or technical guidance regularly for enterprise to transfer advanced technology to cultivate talent for the enterprise and carry out academic exchanges, etc. The patterns of cooperate-running education are different whether they are based on school or on enterprises from country to country, region to region.

\section{THE DIVERSIFIED PERIOD OF THE PROFESSIONAL EDUCATION}

Great changes had been brought to the global economy by the world's spurt of progress of science and technology since1980s. The science and technology with the core of information technology has been developing rapidly all over the world, which directly leads to the fundamental change in the country's industrial structure. Generally speaking, the organization is also undergone a fundamental change as the technical contents in work are more and more, job changes faster and faster. All of these require workers to have both high academic level and skill level to meet the need of high skill jobs and to continue to learn for the constantly changing work. So, it was a restoration and development period for the world's secondary occupation education in 1980s. Since then, people gradually changed the disappointed attitude and gave up the prejudice for education, and began to look at education and occupation education with a more rational attitude; many countries begin to adjust their own occupation education development strategy.

Vocational education has been the key to education development in many countries. $60 \%$ of the 1.6 billion bank loan for education investment between1963-1976 was for occupation education, $50 \%$ of the 5.8 billion bank loan was used to develop different types of occupation education between1977-1986, according to an estimate. Because the unemployment rate has risen in the western developed countries, the school graduates employment rate declined rapidly since $1990 \mathrm{~s}$, as a result, the ratio of students who chose occupation education decreased, therefore, senior occupation education ,as a simple terminal education mode of preparation for employment, which is difficult from adapting to the needs of social development in the world, it has been facing greater challenges with the rapid development in the higher occupation education.

From the specific scale, the proportion of students studied in the occupation school of developed countries $(18.6 \%)$ is almost as two times as that of the developing countries (10.3\%) in 1995.As the number of students learning in the occupation school rose from $6.7 \%$ in 1980 to $10.3 \%$ in 1995 in developing countries, the gap between developing and developed countries will have been shortened Since 1980, regional differences are very obvious In developing countries. In the Latin American and Caribbean countries, occupation school enrollment rate was $25.2 \%$ in 1995 , while it was only $1.2 \%$ in the South Asian region. In many areas, this figure has had No change since 1990, but in Arabia and some countries of East Asia, the figures rose almost $1 / 3$. In some developed countries, senior secondary school education and occupation rate are generally higher, such as $77 \%$ in Austria and Germany, 53\% in France, and J28\% in Japan.[3] (Data are listed in Table 1.)

table I. The Proportion of Students in Public AND Private OCCUPATION EdUCATION IN SENIOR High SCHOOL (\%)IN SOME COUNTRIES

\begin{tabular}{|c|c|c|c|c|}
\hline \multirow{2}{*}{ country } & \multicolumn{2}{|c|}{$\begin{array}{c}\text { The Proportion of Students in Public } \\
\text { and Private Occupation Education in } \\
\text { Senior High School (\%) }\end{array}$} \\
\cline { 2 - 5 } & \multirow{2}{*}{$\begin{array}{c}\text { Genera } \\
\text { lplan }\end{array}$} & \multicolumn{3}{|c|}{ Vocational plan } \\
\cline { 2 - 5 } & sum & $\begin{array}{c}\text { School- } \\
\text { based }\end{array}$ & Combined \\
\hline Australia & 35 & 65 & -- & -- \\
\hline Austria & 23 & 77 & 42 & 35 \\
\hline Belgium & 32 & 68 & 65 & 3 \\
\hline
\end{tabular}




\begin{tabular}{|c|c|c|c|c|}
\hline \multirow{2}{*}{ country } & \multicolumn{3}{|c|}{$\begin{array}{c}\text { The Proportion of Students in Public } \\
\text { and Private Occupation Education in } \\
\text { Senior High School (\%) }\end{array}$} \\
\cline { 2 - 5 } & $\begin{array}{c}\text { Genera } \\
\text { l plan }\end{array}$ & \multicolumn{3}{|c|}{ Vocational plan } \\
\cline { 2 - 5 } & sum & $\begin{array}{c}\text { School- } \\
\text { based }\end{array}$ & Combined \\
\hline Australia & 35 & 65 & -- & -- \\
\hline Czekh & 16 & 84 & 36 & 48 \\
\hline France & 47 & 53 & 43 & 10 \\
\hline Germany & 23 & 77 & 24 & 53 \\
\hline Hungary & 27 & 73 & 46 & 27 \\
\hline Italy & 28 & 72 & 72 & $\mathrm{a}$ \\
\hline Japan & 72 & 28 & 28 & $\mathrm{a}$ \\
\hline South Korea & 57 & 43 & 43 & $\mathrm{n}$ \\
\hline Netherland & 30 & 70 & 47 & 23 \\
\hline portuguese & 76 & 24 & 24 & $\mathrm{a}$ \\
\hline The Russian & 58 & 42 & - & - \\
\hline Federation & 58 & 40 & 38 & 2 \\
\hline Spain & 60 & 43 & - & - \\
\hline Sweden & 44 & 53 & 9 & 60 \\
\hline Switzerland & 31 & 69 & - & - \\
\hline UK & 42 & 58 & - & - \\
\hline
\end{tabular}

(Table symbols: a-unsuited; n-negligible; --unspecified)

Entering the new century, mankind has been ushering in the era of knowledge economy, which is such an era that people changing jobs and occupation more frequently, and many traditional occupations in the community disappeared, at the same time, the new occupations are ceaseless emerging in large numbers, as some researchers said, as the half-life period of modern occupation gets shorter and shorter, therefore, it is more and more difficult for the secondary occupation education to make its choice of the developing direction. More and more countries have to begin to adjust and reform the secondary occupation education, and here came a new period of occupation education with diversification of development strategy and the rising stage of the school-based mode.

In short, diversified mode of vocational education is a new occupation education that with widespread participation of schools, enterprises, governments, kinds of social groups and private individuals. So the subjects in charge are diverse, and the patterns mainly embodied in the state of the society-based mode, enterprise-based mode and cooperative mode, so the division and cooperation among schools, enterprises, governments, society, and private individuals ensured their functioning normally with fully resource sharing. So the form is operated in various ways, including the following flexible mode such as full-time, half time, working-hour, instruction of correspondence, TV correspondence, formal education, informal education and other education forms in different levels for pre- career and post-career training and so on, in order to make the whole staff as an education network.

\section{REFERENCES}

[1] the dialectical relationship between occupation education and economic development.[J]. Education Reference Data, 1996.

[2] Shi Weiping, post-war occupation education development and the current trend.[M].comparative education of occupation Beijing, Beijing Normal University Press, 2001.PP. 225.

[3] The International Labour Office. The world employment report (19981999) $[\mathrm{M}]$. Beijing,The Labour and Social Security Publishing House, 2000:55 